Article

\title{
Sample selection and reasons for non-participation in the PRedictors and Outcomes of incident FRACtures (PROFRAC) study
}

\author{
Amanda L. Stuart, ${ }^{1}$ Julie A. Pasco, ${ }^{1-3}$ Sharon L. Brennan-Olsen, ${ }^{2,4}$ Michael Berk,, ,5,6 \\ Amelia G. Betson, ${ }^{1}$ Katherine E. Bennett, ${ }^{1}$ Elizabeth N. Timney, ${ }^{1}$ Lana J. Williams ${ }^{1}$ \\ ${ }^{1}$ IMPACT Strategic Research Centre, School of Medicine, Barwon Health, Deakin University; ${ }^{2}$ Department \\ of Medicine - Western Health, University of Melbourne; ${ }^{3}$ Department of Epidemiology and Preventive \\ Medicine, Monash University; ${ }^{4}$ Australian Institute for Musculoskeletal Science (AIMSS), Melbourne; \\ ${ }^{5}$ Department of Psychiatry, Florey Institute of Neuroscience and Mental Health, University of Melbourne; \\ ${ }^{6}$ Orygen the National Centre of Excellence in Youth Mental Health, Melbourne, Australia
}

Significance for public health

Fragility fractures associated with osteoporosis are a major public health concern for our aging population. Identifying predictors and consequences of incident fracture is thus imperative if we are to target modifiable risk factors and reduce the burden of disease. This manuscript describes sample selection, cost-effective recruitment methods and reasons for non-participation for the PRedictors and Outcomes of incident FRACtures (PROFRAC) study. Understanding drivers of research participation and barriers to participation is necessary to inform study design to achieve optimal participation in comprehensive samples.

\footnotetext{
Abstract

Background. Fragility fractures, associated with osteoporosis, are an escalating public health problem. We aim to describe sample selection, recruitment methods and reasons for non-participation in The PRedictors and Outcomes of incident FRACtures (PROFRAC) study.

Design and Methods. Barwon Statistical Division residents aged 20+ years, with a radiologically-confirmed fracture between June $1^{\text {st }} 2012$ and May 31 ${ }^{\text {st }} 2013$, were eligible. Individuals identified as fracture cases were invited by mail to complete a questionnaire. Reasons for non-participation were documented. Logistic regression techniques were used to determine odds ratios for participation and non-participation reasons.

Results. A total of 1,458 of 2,155 (67.7\%) adults with fracture (48.7\% men) participated. Individuals were excluded due to inability to give informed consent, death, no knowledge of fracture, or inability to be contacted. The odds of participation decreased with age (OR 0.99, 95\%CI 0.99-0.99, $\mathrm{P}=0.011$ ) and increased among specific fracture groups [clavicle/scapula (OR 2.50, 1.30-4.68, $\mathrm{P}=0.006$ ), forearm/humerus (OR 2.00, 1.22-3.27, $\mathrm{P}=0.006$ ), wrist (OR 2.08, 1.31-3.32, $\mathrm{P}=0.002)$, hip (OR 2.12, 1.20-3.75, $\mathrm{P}=0.009$ ), ankle (OR 1.85, 1.20-2.87, $\mathrm{P}=0.001$ ), compared to face/skull fractures]. The odds of reporting disinterest, time constraints or personal reasons as the reason for non-participation decreased with age, whereas the odds of reporting frailty, language-related issues or illness as the reason for non-participation increased with of age [disinterest (OR 0.98, 0.97-0.98, $\mathrm{P}<0.001$ ), time constraints (OR 0.97, 0.96-0.98, $\mathrm{P}<0.001$ ), personal reasons (OR 0.98, 0.97-0.99, $\mathrm{P}=0.007)$, frailty (OR 1.12, 1.09$1.15, \mathrm{P}<0.001$ ), language-related issues (OR 1.02, 1.01-1.04, $\mathrm{P}<0.001$ ), illness (OR 1.03, 1.02-1.05, $\mathrm{P}<0.001)$ ].
}

Conclusions. Understanding drivers of research participation can inform study design to achieve optimal participation in health research.

\section{Introduction}

Osteoporosis is a common health issue in older adults. Fragility fractures associated with osteoporosis are a major public health problem among both men and women and are responsible for considerable morbidity. ${ }^{1,2}$ It has been estimated fragility fractures account for $0.83 \%$ of the global burden of non-communicable disease. ${ }^{3}$ Fragility fractures are an escalating problem worldwide, ${ }^{3,4}$ for example, in Australia, hip fractures alone, are predicted to increase from 15.2 thousand per year (in 1996) to 60 thousand per year by 2051.5 Loss of health-related quality of life associated with low to moderate energy fracture can persist for 12-18 months post-fracture, ${ }^{6}$ thus identifying predictors and consequences of incident fracture are imperative to identify modifiable risk factors and reduce disease burden. One of the major obstacles to producing good quality research is participant recruitment. Studies with poor recruitment strategies are at risk of non-participant/selection bias and lack of generalizability, which are important for valid epidemiological research. ${ }^{7}$ Investigators have been known to try a variety of recruitment strategies including massmedia/advertising, direct mail out, face-to-face recruitment, mixed modes of data collection, referrals and incentives with varying results. ${ }^{7-11}$ Monetary or prize draw incentives are reported to increase the rate of recruitment substantially; 12 however, this can be unmanageable due to catchment area variance, budgetary constraints and/or ethical, institution- or country-specific restrictions. ${ }^{7,11,13}$ Targeted mail outs are generally cost-effective and are a time-efficient method for successful recruitment, ${ }^{8}$ and follow-up contact such as reminder letters or emails have been shown to increase recruitment rates further. ${ }^{11}$ Other factors, such as questionnaire length, notification prior to mail out and personalised questionnaires may also increase recruitment rates. ${ }^{12}$ To improve recruitment for health studies, researchers have called for transparency in recruitment methods and it has been acknowledged that shared experience can inform recruitment strategies and help reduce associated burden. ${ }^{10,11,13,14}$ With these data in mind, the PRedictors and Outcomes of incident FRACtures (PROFRAC) study has been designed to capture valuable information from a robust source using cost effective methods of recruitment within a strict budget and protocol. Thus, the aim of this paper is to describe sample selection, recruitment methods and reasons for non-participation in the PROFRAC study. 


\section{Design and Methods}

\section{Study design}

PROFRAC is a case-control study designed to examine predictors and consequences of incident fracture in men and women, including lifestyle factors (smoking, physical activity, diet, alcohol), social determinants (education, income, occupation, and housing circumstances) and existing medical co-morbidities and medication usage. The study utilises data from men and women who had sustained an incident fracture (fracture cases) and the Geelong Osteoporosis Study (GOS) participants who had no history of adult fracture (non-fracture controls). This manuscript describes the participation of fracture cases only, further details regarding sampling, recruitment, methodology and outcomes of the GOS are published elsewhere. ${ }^{9}$

\section{Study region}

Cases and controls were recruited from the Barwon Statistical Division (BSD), a geographically well-defined region of southeastern Australia. The region is included within the Commonwealth Electoral Rolls for Corio, Lalor and Corangamite. It is considered to be well suited to epidemiological research as it has a defined population consisting of a range of social, cultural and geographical settings, with a centralised health provider (the University Hospital Geelong) located in Geelong. Approximately 235,000 adults ( 20 years plus) were residing in the region at June $30,2010 .{ }^{15}$ The region is similar in age distribution, country of birth, education, marital status, employment and income profiles to the Australian population, allowing data from this sample to be extrapolated to national levels. ${ }^{9,16}$

\section{Sample selection}

\section{Fracture cases}

All residents of the $\mathrm{BSD}$, aged 20 years and older, with at least one fracture at any skeletal site between June $1^{\text {st }} 2012$ and May $31^{\text {st }}$ 2013 were invited to participate in the current study. Fractures were identified by a daily computerised keyword search of all University Hospital Geelong (Barwon Health) radiological reports. Reports referring to "possible" fracture were not included unless radiologically confirmed at a later date. This method of fracture ascertainment has been previously validated and utilised to document fracture epidemiology in the region. ${ }^{17,18}$ Exclusion criteria included fractures with a pathological origin and/or inability to provide written informed consent. Residents of the catchment area who sustained a subsequent fracture during the study period were invited to participate for the first fracture only. Date and site of subsequent fractures were recorded; however, these participants were not required to complete a second questionnaire. Fracture site was identified and pooled according to body region: 1) face/skull; 2) vertebra; 3) ribs; 4) clavicle/scapula; 5) pelvis; 6) forearm/humerus; 7) wrist; 8) hand/fingers/thumb; 9) hip; 10) femur/patella/tibia/fibula; 11) ankle; and 12) foot/toes. Individuals with multiple fractures from the same event were grouped under multiple fractures. At the end of each month, potential participants were sent a letter of invitation to participate in the study along with the participant information and consent form, reply-paid envelope and the study questionnaire. In conjunction with the mail out, lists of outpatient clinic attendees and hospital ward patients were screened for identified fracture cases, and participation in the study was discussed with these individuals in person during their visit to the hospital. Participants who did not respond by the end of the month were followed up by telephone contact at varying times during work and non-work hours, including weekends. In addition, a second letter of invitation was sent if contact was not able to be made via telephone. A variety of strategies was employed to encourage participation: advertisements detailing the study design were displayed in the University Hospital Geelong's Imaging Department, and on noticeboards throughout the hospital and media coverage by the local newspapers. Hospital staff at the outpatient clinic and wards in which fracture patients were hospitalised were also educated on the study aims and protocol and encouraged to promote the study to eligible persons.

The reason for declining participation was documented and grouped according to the following themes: 1) disinterest (not interested/cannot be bothered/does not want to); 2) frailty (old age/ inability to cope with involvement in the study/inability to understand the study due to age); 3) illness (illness associated with fracture/cancer/other illness); 4) time constraints (work commitments/home commitments/too busy); 5) language-related issues; 6) personal reasons (invasion of privacy/religious or philosophical reasons/personal reasons/dissatisfaction with medical services/already completed another survey); and 7) undeterminable reason (no reason given). Study refusals returned by mail were usually accompanied by a note from the invited person describing the reason for non-participation or were otherwise classified as undeterminable.

\section{Socioeconomic status (SES)}

For each eligible PROFRAC participant, the full residential address was electronically matched to the corresponding Australian Bureau of Statistics (ABS) 2011 census data. ABS reference data were used to determine the Socio-Economic Index For Areas (SEIFA) value from ABS 2011 census data for each participant. ${ }^{19}$ SEIFA indices summarise the characteristics of participants within an area, and provide a single measure to rank the level of advantage and disadvantage at the area level. The Index of Relative Socio-economic Advantage and Disadvantage (IRSAD) score, which accounts for socioeconomic parameters including income and type of occupation, was employed for this study; a low score as measured by the IRSAD indicates, relative to other areas, the most disadvantaged area, while a high score indicates the most advantaged area. ${ }^{19}$ In 2011, approximately 4\% of census areas could not be given a SEIFA score due to low population density in areas, or poor data quality. ${ }^{19}$ SEIFA values were unavailable for 95 ( $4.4 \%$ ) of the 2,155 eligible patients and were thus excluded from this analysis. Validation of the SEIFA indexes have been undertaken by ABS analysts, combined with an external peer review of methodology used in SEIFA 2011. ${ }^{20}$

\section{Study integrity}

Approval to conduct the study was received from the Barwon Health and Deakin University Human Research Ethics Committees. Written informed consent was obtained from all participants. Due to ethical constraints, the only data available for non-participants were reason for non-participation, age, sex, areabased SES and fracture type and date.

\section{Statistical analyses}

Descriptive data are presented, whereby median and interquartile range are provided for continuous non-parametric variables and number (percentage) were employed for categorical variables. The Pearson's chi-square test was used to examine differences between participants and non-participants with regards to categorical variables, and Kruskal-Wallis for non-parametric continuous variables. Binary logistic regression models were used to deter- 
mine the odds ratio (OR) and $95 \%$ confidence intervals $(95 \% \mathrm{CI})$ for i) likelihood of agreeing to participate and ii) non-participation reason. Backwards elimination techniques were employed to determine best models. Statistical analyses were performed using Minitab (version 16; Minitab, State College, PA).

\section{Results}

A total of 3,027 men and women with fracture who presented to the University Hospital Geelong were invited to participate in PROFRAC. Of these, 153 had died, 193 were unable to give informed consent due to cognitive impairment, 451 were unable to be contacted and 75 were unaware of having a fracture. Of the remaining 2,155 (47.6\% men) men and women, 697 declined participation for the following reasons: disinterest (44.5\%), frailty $(15.1 \%)$, illness $(7.1 \%)$, time constraints (12.7\%), language-related issues $(8.6 \%)$, personal reasons $(10.5 \%)$ and undeterminable reason $(1.5 \%)$. A total of 1,458 men and women ( $48.7 \%$ men) agreed to participate in the study (response $67.7 \%$ of eligible participants: $68.5 \%$ for men, $66.9 \%$ for women). Table 1 presents differences between participants and non-participants according to sex, age, SES and skeletal site of fracture and the corresponding participation rate. There was no difference in the proportion of men $(48.7 \%)$ and women $(51.3 \%)$ who participated in the study. However, nonparticipants were older and a higher proportion were in the most disadvantaged SES group. Non-participants had a higher proportion of face/skull and vertebral fractures and participants had a higher proportion of ankle fractures. Low participation rates were evident among those with rib and hand/fingers/thumb fractures, whereas high participation rates were evident for clavicle/scapula, forearm/humerus and wrist fractures, however the difference between participants and non-participants at these sites were not significant.

The odds of participation decreased with age (OR 0.99, 95\% CI $0.99-0.99, \mathrm{P}=0.011)$ and increased among specific fracture groups [clavicle/scapula OR $2.50 \quad 95 \% \mathrm{CI} \quad 1.30-4.68, \quad \mathrm{P}=0.006$, forearm/humerus OR 2.00, 95\%CI 1.22-3.27, $\mathrm{P}=0.006$, wrist $\mathrm{OR}$ $2.08,95 \%$ CI 1.31-3.32, $\mathrm{P}=0.002$, hip OR 2.12, 95\%CI 1.20-3.75, $\mathrm{P}=0.009$, ankle OR $1.85,95 \% \mathrm{CI} 1.20-2.87, \mathrm{P}=0.001$, compared to face/skull fractures]. SES and sex did not affect these results.

The odds of reporting disinterest, or personal reasons as the reason for non-participation decreased with age, whereas the odds of reporting frailty or illness as the reason for non-participation increased with of age (Table 2). The odds of reporting time constraints as the reason for non-participation decreased with age and was increased among higher SES quintiles. Whereas the odds of reporting language-related issues as the reason for non-participation increased with age and decreased incrementally with each quintile of SES. Small numbers prevented further investigation into the drivers behind reporting an undetermined reason for nonparticipation.

Table 1. Participation rate and differences in characteristics between participants and non-participants.

\begin{tabular}{|c|c|c|c|c|c|}
\hline Group & $\begin{array}{c}\text { Participation rate, } \\
\%\end{array}$ & $\begin{array}{l}\text { All fracture patients, } \\
n=2155\end{array}$ & $\begin{array}{c}\text { Participants } \\
\mathrm{n}=1458\end{array}$ & $\begin{array}{c}\text { Non-participants } \\
\mathrm{n}=697\end{array}$ & P value \\
\hline Sex, male & 68.5 & $1026(48.0)$ & $703(48.7)$ & $323(46.5)$ & 0.42 \\
\hline $\begin{array}{c}\text { Age at fracture } \\
\text { 20-29 years } \\
30-39 \text { years } \\
40-49 \text { years } \\
\text { 50-59 years } \\
\text { 60-69 years } \\
\text { 70-79 years } \\
\text { 80+ years }\end{array}$ & $\begin{array}{l}68.1 \\
70.0 \\
68.9 \\
70.4 \\
72.0 \\
64.2 \\
60.4\end{array}$ & $\begin{array}{l}310(14.4) \\
270(12.5) \\
280(13.0) \\
321(14.9) \\
349(16.1) \\
282(13.1) \\
346(16.1)\end{array}$ & $\begin{array}{l}211(14.5) \\
189(13.0) \\
193(13.2) \\
226(15.5) \\
249(17.1) \\
181(12.4) \\
209(14.3)\end{array}$ & $\begin{array}{c}99(14.2) \\
81(11.6) \\
87(12.5) \\
95(13.6) \\
97(13.9) \\
101(14.5) \\
137(19.7)\end{array}$ & 0.02 \\
\hline Age at fracture, Continuous, years & - & $57.5,38.4-73.4$ & $56.6,38.2-71.3$ & $59.0,39.2-77.1$ & 0.02 \\
\hline $\begin{array}{l}\text { Socioeconomic status } \\
\text { Quintile } 1 \text { (most disadvantaged) } \\
\text { Quintile } 2 \\
\text { Quintile } 3 \\
\text { Quintile } 4 \\
\text { Quintile } 5\end{array}$ & $\begin{array}{l}62.6 \\
66.0 \\
68.3 \\
70.0 \\
74.5\end{array}$ & $\begin{array}{l}463(22.5) \\
412(20.0) \\
590(28.6) \\
387(18.8) \\
208(10.1)\end{array}$ & $\begin{array}{l}290(20.9) \\
272(19.6) \\
403(29.0) \\
271(19.5) \\
155(11.1)\end{array}$ & $\begin{array}{l}173(25.9) \\
140(20.9) \\
187(28.0) \\
116(17.3) \\
53(7.9)\end{array}$ & 0.02 \\
\hline $\begin{array}{l}\text { Fracture site (\% single fracture only) } \\
\text { Face/skull } \\
\text { Vertebra } \\
\text { Rib } \\
\text { Clavicle/scapula } \\
\text { Pelvis } \\
\text { Forearm/humerus } \\
\text { Wrist } \\
\text { Hand/fingers/thumb } \\
\text { Hip } \\
\text { Femur/patella/tibia/fibula } \\
\text { Ankle } \\
\text { Foot/toes }\end{array}$ & $\begin{array}{l}55.4 \\
59.9 \\
59.6 \\
75.8 \\
61.4 \\
72.3 \\
72.3 \\
63.0 \\
69.5 \\
69.6 \\
74.8 \\
68.9\end{array}$ & $\begin{array}{c}92(4.6) \\
177(8.9) \\
104(5.2) \\
66(3.3) \\
44(2.2) \\
213(10.7) \\
318(15.9) \\
273(13.7) \\
118(5.9) \\
135(6.8) \\
202(10.1) \\
257(12.9)\end{array}$ & $\begin{array}{c}51(3.8) \\
106(7.8) \\
62(4.6) \\
50(3.7) \\
27(2.0) \\
154(11.4) \\
230(17.0) \\
172(12.7) \\
82(6.1) \\
94(6.9) \\
151(11.1) \\
177(13.1)\end{array}$ & $\begin{array}{c}41(6.4) \\
71(11.0) \\
42(6.5) \\
16(2.5) \\
17(2.6) \\
59(9.2) \\
88(13.7) \\
101(15.7) \\
36(5.6) \\
41(6.4) \\
51(7.9) \\
80(12.4)\end{array}$ & $\begin{array}{l}0.01 \\
0.02 \\
0.07 \\
0.16 \\
0.35 \\
0.14 \\
0.06 \\
0.07 \\
0.69 \\
0.64 \\
0.03 \\
0.70\end{array}$ \\
\hline Multiple fractures & 65.4 & $156(7.2)$ & $102(7.0)$ & $54(7.8)$ & 0.53 \\
\hline
\end{tabular}

Results presented as percent (\%), median, interquartile range or $n$ (\%). Missing data: SES $n=95$, Fracture site $n=156$ (multiple fractures). 


\section{Discussion}

This study reports a participation of $67.7 \%$ amongst eligible participants. The most frequent reason for non-participation was disinterest, followed by frailty, time constraints, personal reasons, language-related issues, illness, and then undeterminable reasons. Age was a major factor in the reason for non-participation, increasing the odds of reporting frailty, language-related issues and illness but decreasing the odds of reporting disinterest, time constraints and personal reasons. Overall, participation was influenced by age and fracture site. Interestingly, there was no difference in the overall number of male and female participants.

Studies utilising individuals from the same region have also yielded good recruitment and retention when utilising similar recruitment strategies such as direct mail outs. ${ }^{8,9}$ Previously, a cohort of fracture patients, aged 35 and older, were recruited from the same region reporting a participation rate of $77 \% .{ }^{21}$ Similarly, the Geelong Osteoporosis Study reported a participation rate of $77 \%$ for the female cohort and $67 \%$ for the male cohort, although participants were recruited from the population not on the basis of fracture status. ${ }^{8,9}$

A Cochrane review by Edwards et al. has reported that both monetary incentives and non-monetary incentives, shorter length of questionnaire, hand written addresses, pre-notification, followup contact and assurance of confidentiality all improve participation rates in health studies. ${ }^{12}$ Unfortunately, the number of participants and budget of the current study prevented hand-writing addresses on envelopes and using monetary incentives. Also, for comprehensive investigation of risk factors and outcomes associated with fracture the amount of information collected for the current study meant the length of questionnaire was rather long. However, assurance of confidentiality, follow-up contact and pre-notification of contact were all part of the protocol for the current study. The pre-notification was in the form of advertisement posters displayed throughout the hospital, local newspaper coverage and education of hospital staff working with fracture patients. Home visits are another possible avenue to improve participation however, budgetary constraints prevented this in our case.

Akin to the Geelong Osteoporosis Study, ${ }^{10}$ being disinterested was the most commonly cited reason for non-participation. However, this has not been the most common reason for non-participation in other studies. An investigation into the NordTrøndelag Health Study (HUNT 3) study, reported the most common reason for non-participation was lack of time or inconvenience, which was reported by $50.7 \%$ of non-participating women and $56.6 \%$ of non-participating men. ${ }^{22}$ In contrast, lack of perceived benefit, distrust and poor health were reported as the most common reasons for non-participation amongst frail older adults in a systematic review investigating challenges and strategies for recruitment of the frail elderly. ${ }^{14}$ In this study, we identified that the non-participants were older than the participants, however there was still strong participation up until age 70 . The elderly are often under-represented in population-based studies and, given the ageing population, this demographic should be targeted..$^{23}$

Galea (2007) cited four main reasons for decreased participation in epidemiological studies over time: an increase in invitations to other research projects, a decreased desire to volunteer in projects without direct personal benefit, diminishing enthusiasm to science in general, and the increasing burden of time to the participant. Aside from time constraints, which explained 13\% of nonparticipation in the current study, Galea's reasons for non-participation may have been encompassed in our disinterested category. Otmar and colleagues ${ }^{24}$ investigated cultural models of osteoporosis in the same study region as the current study, and showed that osteoporosis is considered to be of low salience in the community which might explain the disinterest shown by some of the individuals approached to participate in the study. Reporting of disinterest for the reason for non-participation was influenced by age, whereby younger adults were more likely to cite it. This is most likely due to the public perception that fragility fracture, an outcome of osteoporosis, is commonly thought to be associated with old age.

Lack of understanding of the research process, importance of research and health literacy have all been identified as potential barriers to participation for patients in lower SES groups. ${ }^{25}$ The HUNT 3 study found lower participation amongst the most disadvantaged group. ${ }^{23}$ Similarly, the lowest participation rate was seen in the lowest SES group in the current study, however these participants contributed to one-fifth of the overall participant group, thus are still well represented. It has been consistently reported that individuals from higher SES groups are more likely to participate in research studies ${ }^{7,22}$ and our study is no exception. Surprisingly, the highest participation rate seen in the highest SES group (quintile 5) equates to only $11 \%$ of the overall group. The largest amount of fractures occurred in the middle SES group (quintile 3 ) and thus the greatest proportion of participants was from this group. Although we found differences in SES quintiles between participants and non-participants in the unadjusted analyses, SES did not remain in the final model with age and fracture type. Higher SES was found to increase the odds of reporting time constraints and decrease the odds of reporting language-related issues as the reason for non-participation.

Differences in participation by fracture site were observed; notably, non-participants had a higher proportion of face/skull and vertebral fractures. The lower number of participants with face/skull and clinical vertebral fractures who participated in the PROFRAC study may be indicative of the overall health of the patient, or the cause of fracture. Road traffic accidents, assault and falls are the most common causes of maxillofacial injuries, ${ }^{26}$ each

Table 2. Logistic regression models for predicting reason for non-participation. Results are presented as odds ratio (OR) and 95\% confidence intervals $(95 \% \mathrm{CI})$.

\begin{tabular}{|c|c|c|c|c|c|c|c|}
\hline & & Disinterest & Frailty & Time constraints & Personal reasons & Language-related issues & Illness \\
\hline Model 1 & Age & $0.98(0.97-0.98)^{*}$ & $1.12(1.09-1.15)^{*}$ & $0.97(0.96-0.98)^{*}$ & $0.98(0.97-0.99)^{* *}$ & $1.02(1.01-1.04)^{*}$ & $1.03(1.02-1.05)^{*}$ \\
\hline \multirow[t]{6}{*}{ Model 2} & $\begin{array}{l}\text { Age } \\
\text { SES }\end{array}$ & $0.97(0.96-0.98)^{*}$ & $1.12(1.10-1.15)^{*}$ & $0.97(0.96-0.98)^{*}$ & $0.99(0.98-0.99)^{* * *}$ & $1.02(1.01-1.04)^{*}$ & $1.03(1.02-1.05)^{*}$ \\
\hline & Quintile 1 (referent) & - & - & - & - & - & - \\
\hline & Quintile 2 & $0.82(0.51-1.32)$ & $1.44(0.70-3.0)$ & $2.83(1.25-6.42)^{* * *}$ & $0.70(0.33-1.47)$ & $0.40(0.19-0.85)^{* * *}$ & $1.36(0.60-3.09)^{* * *}$ \\
\hline & Quintile 3 & $1.4(0.92-2.19)$ & $1.17(0.57-2.38)$ & $2.29(1.04-5.05)^{* * *}$ & $0.59(0.29-1.20)$ & $0.34(0.16-0.70)^{* * *}$ & $0.80(0.34-1.88)^{* * *}$ \\
\hline & Quintile 4 & $0.81(0.49-1.33)$ & $1.04(0.44-2.47)$ & $4.47(2.02-9.89)^{* * *}$ & $0.89(0.42-1.85)$ & $0.29(0.11-0.73)^{* * *}$ & $1.06(0.41-2.72)^{* * *}$ \\
\hline & Quintile 5 & $0.77(0.40-1.47)$ & $1.69(0.56-5.08)$ & $3.48(1.33-9.12)^{* * *}$ & $1.60(0.67-3.67)$ & $0.11(0.01-0.81)^{* * *}$ & $1.06(0.41-2.72)^{* * *}$ \\
\hline
\end{tabular}

${ }^{*} \mathrm{P}<0.001,{ }^{*} \mathrm{P}<0.01,{ }^{* * *} \mathrm{P}<0.05$. 
of which have associated psychological distress that may impact on the decision to participate in research. Bed rest and limited movement associated with treatment for vertebral fractures, ${ }^{27} \mathrm{com}$ bined with the resulting pain from the fracture may have decreased the desire and/or ability to participate in research. However, we note that this was not evident for participation among those with hip fracture.

A large proportion of potential participants were excluded for reasons including death, inability to give informed consent, no knowledge of fracture and inability to be contacted. Risk of death following fracture is increased immediately after fracture, and has

Correspondence: Lana J. Williams, IMPACT Strategic Research Centre, School of Medicine, Deakin University, PO Box 281, Geelong Victoria 3220, Australia.

Tel.: +61.342153303 .

E-mail: lanaw@barwonhealth.org.au

Key words: recruitment, non-participation, sample selection, fracture, participation rate.

Acknowledgments: the authors would like to thank the participants involved in this study.

Contributions: LJW, SLB-0, MB and JAP conceived and designed the study. ALS performed the statistical analysis and ALS and LJW drafted the manuscript. AGB, KEB and ENT collected data and critically revised the manuscript. LJW takes responsibility for the integrity of the study. All authors revised, read and approved the final manuscript.

Conflict of interests: ALS, AGB, KEB and ENT have no conflicts of interest. JAP has received grant/research support from the NHMRC, BUPA Foundation, Deakin University, Barwon Health and the Western Alliance Academic Health Sciences Centre. SLB-0 has received Grant/Research support from the Barwon Orthopaedic Research Unit, Deakin University, The University of Melbourne, Arthritis Australia, Arthritis Victoria, City of Greater Geelong, Australian Association of Gerontology, and the Victorian Orthopaedic Research Trust, and speaker fees from Amgen Australia and Pfizer Australia. MB has received Grant/Research Support from Bristol Myers Squibb, Eli Lilly, GlaxoSmithKline, Organon, Novartis, MaynePharma and Servier and has been a speaker for AstraZeneca, Bristol Myers Squibb, Eli Lilly, GlaxoSmithKline, Janssen Cilag, Lundbeck, Merck, Pfizer, SanofiSynthelabo, Servier, Solvay and Wyeth, and served as a consultant to AstraZeneca, Bristol Myers Squibb, Eli Lilly, GlaxoSmithKline, Janssen Cilag, Lundbeck, Merck and Servier. LJW has received Grant/Research support from Eli Lilly, Pfizer, The University of Melbourne, Deakin University and the NHMRC.

Funding: This work was funded by the National Health and Medical Research Council (NHMRC), of Australia (1009367, 1162867). LJW and SLB-0 were supported by NHMRC Career Development Fellowships (1064272, and 1107510 , respectively). MB is supported by a National Health and Medical Research Council (NHMRC) Senior Principal Research Fellowship (1059660 and 1156072). The funding providers played no role in the design or conduct of the study; collection, management, analysis, and interpretation of the data; or in preparation, review, or approval of the manuscript.

Received for publication:18 September 2018.

Revision received: 4 April 2019.

Accepted for publication: 12 April 2019

(C) Copyright A.L. Stuart et al., 2019

Licensee PAGEPress, Italy

Journal of Public Health Research 2019;8:1475

doi:10.4081/jphr.2019.1475

This work is licensed under a Creative Commons Attribution NonCommercial 4.0 License (CC BY-NC 4.0). been shown to remain elevated for a decade following the fracture, ${ }^{28,29}$ therefore a decline in number of eligible participants was likely. The issue of the individual having no knowledge of the fracture was difficult to tackle. It is beyond the scope of the role, as researchers, to discuss results with patients, so it was decided a priori to exclude participants who were unaware of the presence of fractures - these were largely clinical vertebral fractures. This minor limitation is acknowledged, as unrecognised vertebral fractures have been associated with impaired wellbeing and physical function. ${ }^{30}$ Although an effort was made to contact patients during non-work hours, including week nights and weekends, there were 451 patients who were coded as unable to be contacted. Tajeu (2013) reported that patients with hip fracture were up to four-fold more likely to require long-term nursing facility care compared with matched comparators one year on, and Galea (2007) suggested that longer working hours make it difficult to contact participants. These factors may have contributed to the difficulty in locating some patients.

\section{Conclusions}

This manuscript highlights characteristics of non-participants in a large fracture sample that included sex, socio-economic factors, fracture site, sample selection and methods of recruitment. Fracture site and age were the strongest predictors of non-participation and thus form the groups that require more intensive attention when recruiting. Understanding drivers of research participation is necessary to inform the design of studies to achieve optimal participation in health research.

\section{References}

1. Pasco JA, Sanders KM, Hoekstra FM, et al. The human cost of fracture. Osteoporos Int 2005;16:2046-52.

2. Otmar R, Kotowicz MA, Brennan SL, et al. Personal and Psychosocial Impacts of Clinical Fracture in Men. J Men's Health 2013;10:22-7.

3. Johnell O, Kanis JA. An estimate of the worldwide prevalence and disability associated with osteoporotic fractures. Osteoporos Int 2006;17:1726-33.

4. Watts JJ, Abimanyi-Ochom J, Sanders KM. Osteoporosis costing all Australians: A new burden of disease analysis - 2012 to 2022. Melbourne, Osteoporosis Australia; 2013. Contract No.: ISBN 978-0-9923698-1-1.

5. Sanders KM, Nicholson GC, Ugoni AM, et al. Health burden of hip and other fractures in Australia beyond 2000. Projections based on the Geelong Osteoporosis Study. Med J Austral 1999;170:467-70.

6. Abimanyi-Ochom J, Watts JJ, Borgstrom F, et al. Changes in quality of life associated with fragility fractures: Australian arm of the International Cost and Utility Related to Osteoporotic Fractures Study (AusICUROS). Osteoporos Int 2015;26:1781-90.

7. Galea S, Tracy M. Participation rates in epidemiologic studies. Ann Epidemiol 2007;17:643-53.

8. Sanders KM, Stuart AL, Merriman EN, et al. Trials and tribulations of recruiting 2,000 older women onto a clinical trial investigating falls and fractures: Vital D study. BMC Med Res Methodol 2009;9:78.

9. Pasco JA, Nicholson GC, Kotowicz MA. Cohort Profile: Geelong Osteoporosis Study. Int J Epidemiol 2012;41:156575. 
10. Markanday S, Brennan SL, Gould H, Pasco JA. Sex-differences in reasons for non-participation at recruitment: Geelong Osteoporosis Study. BMC Res Notes 2013;6:104.

11. Toledano MB, Smith RB, Brook JP, et al. How to Establish and Follow up a Large Prospective Cohort Study in the 21st Century-Lessons from UK COSMOS. Plos One 2014;10: e0131521.

12. Edwards PJ, I. R, Clarke MJ, DiGuiseppi C, et al. Methods to increase response to postal and electronic questionnaires (Review). Cochrane Database Syst Rev. 2009;MR000008.

13. Huynh L, Johns B, Liu SH, et al. Cost-effectiveness of health research study participant recruitment strategies: a systematic review. Clin Trials 2014;11:576-83.

14. Provencher V, Mortenson WB, Tanguay-Garneau L, et al. Challenges and strategies pertaining to recruitment and retention of frail elderly in research studies: a systematic review. Arch Gerontol Geriatr 2014;59:18-24.

15. Australian Bureau of Statistics. ABS National Regional Profile: Barwon (Statistical Division) Available from: http://www.abs.gov.au/AUSSTATS/abs@nrp.nsf/Previouspro ducts/210Population/People12006-2010?opendocument\&tabname $=$ Summary \& prodno $=210 \&$ issue $=2006-2010$.

16. Henry MJ, Pasco JA, Nicholson GC, et al. Prevalence of osteoporosis in Australian women: Geelong Osteoporosis Study. J Clin Densitom 2000;3:261-8.

17. Pasco JA, Henry MJ, Gaudry TM, et al. Identification of incident fractures: the Geelong Osteoporosis Study. Aust NZ J Med 1999;29:203-6.

18. Pasco JA, Lane SE, Brennan-Olsen SL, et al. The Epidemiology of Incident Fracture from Cradle to Senescence. Calcif Tissue Int 2015;97:568-76.

19. ABS. 2011 Socio-Economic Indexes for Areas (SEIFA) Technical Paper Canberra, Australia: ABS. Report No.: Cat 2033.0.055.001.

20. Brennan SL, Lane SE, Lorimer M, et al. Associations between socioeconomic status and primary total knee joint replacements performed for osteoarthritis across Australia 2003-10: data from the Australian Orthopaedic Association National
Joint Replacement Registry. BMC Musculoskelet Disord 2014; 15:356.

21. Sanders KM, Pasco JA, Ugoni AM, et al. The exclusion of high trauma fractures may underestimate the prevalence of bone fragility fractures in the community: the Geelong Osteoporosis Study. J Bone Min Res 1998;13:1337-42.

22. Langhammer A, Krokstad S, Romundstad P, et al. The HUNT study: participation is associated with survival and depends on socioeconomic status, diseases and symptoms. BMC Med Res Methodol 2012;12:143.

23. Pasco JA, Holloway KL, Brennan SL. Characteristics of Female Nonagenarian Participants in an Observational Health Study. J Gerontol Geriatr Res 2014;3:184.

24. Otmar R, Reventlow SD, Nicholson GC, et al. A Cultural Models Approach to Osteoporosis Prevention and Treatment. Sage Open. 2012.

25. Bonevski B, Randell M, Paul C, et al. Reaching the hard-toreach: a systematic review of strategies for improving health and medical research with socially disadvantaged groups. BMC Med Res Methodol 2014;14:42.

26. Boffano P, Kommers SC, Karagozoglu KH, Forouzanfar T. Aetiology of maxillofacial fractures: a review of published studies during the last 30 years. Br J Oral Maxillofac Surg 2014;52:901-6.

27. Dewar C. Diagnosis and treatment of vertebral compression fractures. Radiol Technol. 2015;86:301-20.

28. Melton LJ 3rd, Achenbach SJ, Atkinson EJ, et al. Long-term mortality following fractures at different skeletal sites: a population-based cohort study. Osteoporos Int 2013;24:1689-96.

29. Bliuc D, Alarkawi D, Nguyen TV, et al. Risk of subsequent fractures and mortality in elderly women and men with fragility fractures with and without osteoporotic bone density: the Dubbo Osteoporosis Epidemiology Study. J Bone Min Res 2015;30:637-46.

30. Pasco JA, Henry MJ, Korn S, et al. Morphometric vertebral fractures of the lower thoracic and lumbar spine, physical function and quality of life in men. Osteopor Int 2009;20:787-92. 